\title{
Water and electrolyte abnormalities in the human brain after severe intrapartum asphyxia
}

\author{
J. M. ANDERSON AND N. R. BELTON \\ From the Departments of Pathology and Child Life and Health, \\ Royal Hospital for Sick Children and the University, Edinburgh
}

SYNOPSIS In a necropsy study of brain water, sodium, and potassium concentrations in newborn infants, abnormalities were found in 10 out of 16 cases who were severely asphyxiated at birth. It is concluded that, although frank cerebral cortical necrosis is not often recognizable in perinatal deaths, early anoxic-ischaemic cerebral damage is frequent after intrapartum asphyxia. Diffuse cerebral swelling was associated with marked electrolyte disturbances and may be regarded as a feature of anoxic-ischaemic encephalopathy in asphyxiated newborn infants.

Oedema of the mature human brain is a wellrecognized pathological phenomenon which may occur in response to a variety of agencies including ischaemia and trauma. Clinical observations have indicated that cerebral oedema may also develop in newborn infants, particularly as a complication of intrapartum asphyxia (Brown et $a l .$, in preparation) and supporting pathological evidence of brain swelling has been described in neonatally deceased infants (Pryse-Davies and Beard, 1973). However, the pathogenesis of this brain swelling is poorly understood and there is no information on the biochemical composition of oedematous human infant brain.

Experiments with fetal monkeys have confirmed that prolonged partial intrauterine asphyxia may induce brain swelling (Myers et al., 1969) and have shown that this is associated with disturbances in brain water and electrolyte concentration (Selzer et al., 1972). Brain water and electrolyte abnormalities have also been found in asphyxiated fetal rats (Adlard and De Souza, 1973). To establish whether similar water and electrolyte changes are detectable in perinatally deceased human subjects we have examined samples of brain tissue from a series of asphyxiated infants including four who had developed pathological features of brain swelling.

\section{METHODS}

The series consisted of 26 infants of gestation $32-42$
TABLE 1

CLINICAL AND NECROPSY FINDINGS

\begin{tabular}{|c|c|c|}
\hline & \multicolumn{2}{|c|}{ Group (no. of cases) } \\
\hline & Control & $\begin{array}{c}\text { Birth } \\
\text { asphyxia }\end{array}$ \\
\hline Total no. of cases & 10 & 16 \\
\hline Gestation 32-37 weeks & 5 & 3 \\
\hline Gestation 38-42 weeks & 5 & 13 \\
\hline Fetal distress recognized in labour & $\mathbf{0}$ & 10 \\
\hline $\begin{array}{l}\text { Mode of delivery } \\
\text { a. Spontaneous vertex }\end{array}$ & 5 & 6 \\
\hline b. Assisted vertex & 2 & 4 \\
\hline c. Breech & 1 & 1 \\
\hline d. Caesarean section & 2 & 5 \\
\hline \multicolumn{3}{|l|}{ Primary necropsy findings } \\
\hline \multicolumn{3}{|l|}{ Asphyxial deaths } \\
\hline a. Petechiae on serous surfaces & $\mathbf{0}$ & 4 \\
\hline $\begin{array}{l}\text { b. Multiple visceral infarcts/pulmonary } \\
\text { haemorrhage }\end{array}$ & $\mathbf{0}$ & 8 \\
\hline \multicolumn{3}{|l|}{ Hyaline membrane disease/pulmonary } \\
\hline haemorrhage & 7 & 3 \\
\hline Congenital heart disease & 1 & 1 \\
\hline Meningitis ( $E$. coli) & 1 & $\mathbf{0}$ \\
\hline Congenital hydronephrosis & 1 & $\mathbf{0}$ \\
\hline
\end{tabular}

weeks, freshly stillborn or dying in the neonatal period, divided into two groups on the basis of the Apgar score at birth (Apgar, 1953). Ten infants were normal or were mildly asphyxiated with an Apgar score of 8-10 at 5 minutes of age; five of these infants were intubated for a short period immediately after birth but rapidly established spontaneous breathing, while the remainder did not require resuscitation other than the usual measures to clear the airway. Tissue water and electrolyte concentra- 
tions from these cases were used as control values. The remaining 16 infants were severely asphyxiated and had Apgar scores in the range $0-4$ at 1 minute and $0-7$ at 5 minutes after birth; three of these infants were not resuscitated and were stillborn, while all of the other cases in this group were intubated and many received cardiac massage. The incidence of fetal distress in labour, abnormalities of delivery and the principal findings at necropsy in the two groups are given in Table 1 . Three infants, one in the control group and two in the severely asphyxiated group (see cases 2 and 12, Table 3 ) showed evidence of cranial trauma - that is, lacerations of tentorium cerebelli and subdural haemorrhage. No infant with malformations of the brain was included in the series. The interval from death to necropsy ranged from 14 to 78 hours, with a mean interval of 41 hours for control infants and $\mathbf{4 0}$ hours for asphyxiated infants.

Necropsies were performed and samples collected by one of us (J.M.A.). After a preliminary inspection of the brain, samples of cerebral cortex, free of meninges, were taken from the anterior and posterior poles of one hemisphere; these samples inevitably included a small quantity of digitate white matter. Coronal cuts were made through the same hemisphere at the level of the optic chiasma and posterior to the splenium of the corpus callosum, the cerebrospinal fluid allowed to drain away and the cut surfaces blotted lightly; samples of central white matter were then obtained from frontal and occipital lobes. A portion of muscle was taken from quadriceps femoris.

To measure water concentration, the samples were weighed and dried to constant weight at $105^{\circ} \mathrm{C}$. The residue was digested with concentrated nitric acid, reduced to ash at $425^{\circ} \mathrm{C}$, and redissolved in dilute nitric acid. Sodium and potassium concentrations were measured using an atomic absorption spectrophotometer (Unicam SP 90).

As treatment for clinical cerebral oedema, five infants in the severely asphyxiated group received intramuscular dexamethasone in a dose of 1-2 mg six hourly - that is, approximately $1-2.5 \mathrm{mg} / \mathrm{kg}$ body weight/day. This treatment was commenced within 12 hours of birth in four cases, and on the second day of life in the other case.

\section{RESULTS}

NEUROPATHOLOGICAL FINDINGS Diffuse brain swelling characterized by increased tension of the dura mater of the vault, pallor and flattening of cerebral gyri, and reduction in the size of the ventricles was found in four infants in the severely asphyxiated group. In one of these infants (see case 1, Table 3) the vertical aspect of almost the whole of the cerebrum was extremely soft indicating that infarction had occurred. Cortical softening was not recognized in other brains in the study, but punctate cortical haemorrhage was present in two brains from the severely asphyxiated group (see cases 2 and 13, Table 3). No brains from the control group showed swelling, cortical necrosis, or cortical haemorrhage. Small foci of periventricular white matter necrosis were seen in two brains, one from the control group, and one from the asphyxiated group (see case 8 , Table 3 ), but affected areas were not included in the samples.

TABLE 2

WATER AND ELECTROLYTE CONCENTRATIONS IN BRAIN AND SKELETAL MUSCLE IN CONTROL INFANTS

\begin{tabular}{|c|c|c|c|c|c|c|c|}
\hline \multirow[t]{2}{*}{$\begin{array}{l}\text { Gestation } \\
\text { (weeks) }\end{array}$} & \multirow{2}{*}{$\begin{array}{c}\text { No. } \\
\text { of } \\
\text { cases }\end{array}$} & \multicolumn{2}{|c|}{$\begin{array}{c}\text { Water } \\
(\mathrm{g} / \mathrm{kg} \text { dry weight })\end{array}$} & \multicolumn{2}{|c|}{$\begin{array}{c}\text { Sodium } \\
(m M / k g \text { dry weight })\end{array}$} & \multicolumn{2}{|c|}{$\begin{array}{c}\text { Potassium } \\
(m M / k g \text { dry weight })\end{array}$} \\
\hline & & Mean $\pm 1 S D$ & $\begin{array}{l}\text { Correlation } \\
\text { coefficient: } \\
\text { water conc./ } \\
\text { gestational age }\end{array}$ & Mean $\pm 1 S D$ & $\begin{array}{l}\text { Correlation } \\
\text { coefficient: } \\
\text { sodium conc./ } \\
\text { gestational age }\end{array}$ & Mean $\pm 1 S D$ & $\begin{array}{c}\text { Correlation } \\
\text { coefficient: } \\
\text { potassium conc./ } \\
\text { gestational age }\end{array}$ \\
\hline \multicolumn{8}{|c|}{ Cerebral cortex* } \\
\hline $\begin{array}{l}32-37 \\
38-42\end{array}$ & $\begin{array}{l}5 \\
5\end{array}$ & $\left.\begin{array}{l}9,350 \pm 510 \\
8,390 \pm 650\end{array}\right\}$ & -0.67 & $\left.\begin{array}{c}1,019 \pm 98 \\
831 \pm 188\end{array}\right\}$ & -0.59 & $\left.\begin{array}{l}513 \pm 80 \\
542 \pm 89\end{array}\right\}$ & $0 \cdot 22$ \\
\hline \multicolumn{8}{|c|}{ Cerebral white matter* } \\
\hline $\begin{array}{l}32-37 \\
38-42\end{array}$ & $\begin{array}{l}5 \\
5\end{array}$ & $\left.\begin{array}{l}10,780 \pm 410 \\
10,160 \pm 720\end{array}\right\}$ & -0.52 & $\left.\begin{array}{l}1,251 \pm 244 \\
1,033 \pm 206\end{array}\right\}$ & -0.56 & $\left.\begin{array}{l}594 \pm 94 \\
662 \pm 142\end{array}\right\}$ & 0.48 \\
\hline \multicolumn{8}{|c|}{ Skeletal muscle } \\
\hline $\begin{array}{l}32-37 \\
38-42\end{array}$ & $\begin{array}{l}5 \\
5\end{array}$ & $\left.\begin{array}{l}5.040 \pm 230 \\
5,010 \pm 400\end{array}\right\}$ & $-0 \cdot 32$ & $\left.\begin{array}{l}441 \pm 50 \\
432 \pm 72\end{array}\right\}$ & $-0 \cdot 20$ & $\left.\begin{array}{l}362 \pm 58 \\
376 \pm 77\end{array}\right\}$ & -0.07 \\
\hline
\end{tabular}

* Calculated from the means of frontal and occipital concentrations. 


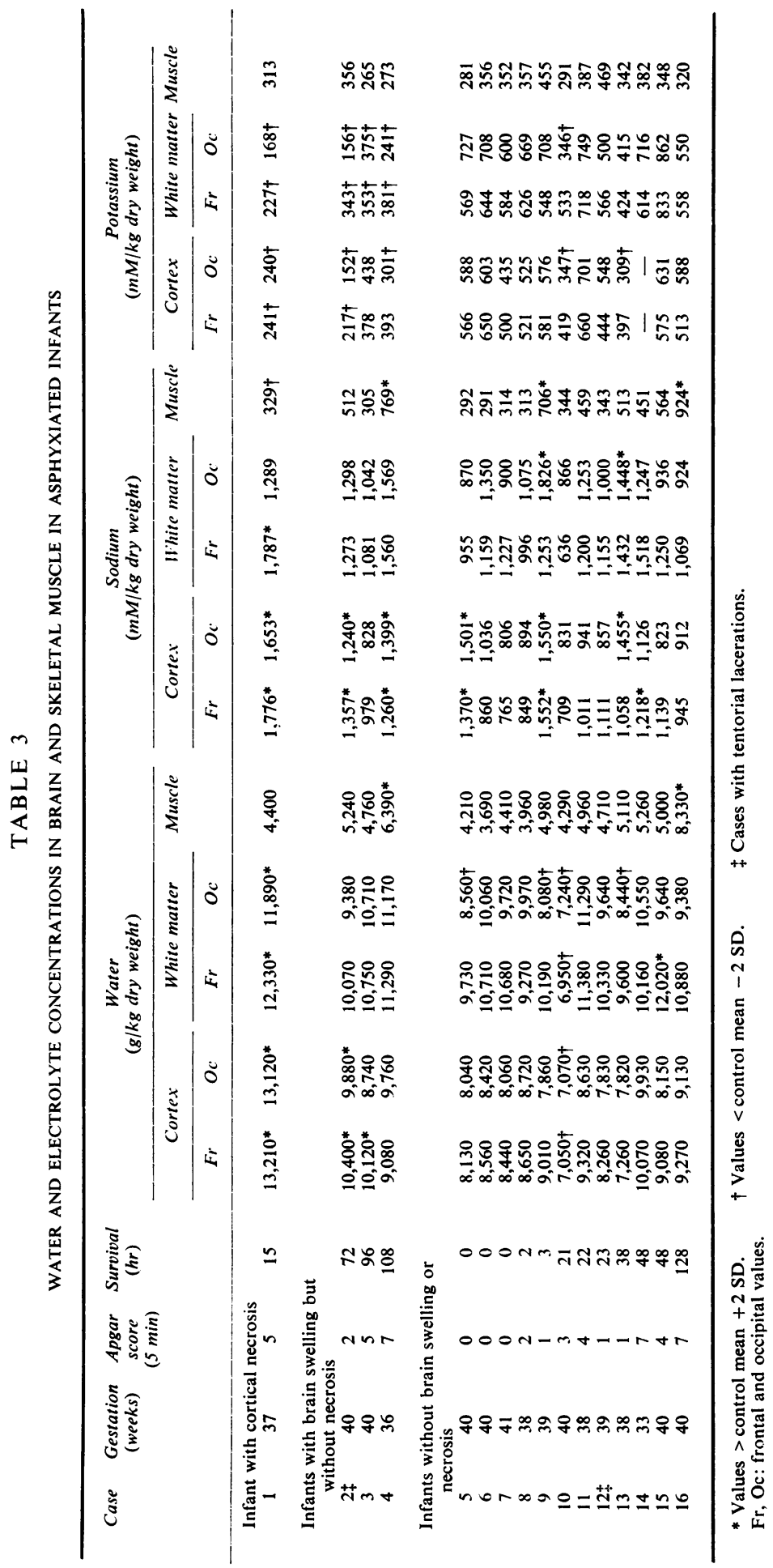


WATER AND ELECTROLYTE ABNORMALITIES Water, sodium, and potassium concentrations in brain and muscle samples from the control group are shown in Table 2. Mean values and standard deviations (SD) were calculated for two gestational age groups, 32-37 weeks and 38-42 weeks, because a decrease in brain water and sodium concentration and an increase in brain potassium concentration was found to occur with increasing maturity.

Table 3 lists the water and electrolyte values obtained from the infants in the asphyxiated group. In the infant with cerebral cortical necrosis (case 1) a marked increase in brain water and sodium concentrations and a decrease in potassium concentration were demonstrated. Values outside the control mean $\pm 2 \mathrm{SD}$ ranges were also frequent in samples from infants without cerebral necrosis but showing signs of brain swelling: $44 \%$ of the brain sample values in these cases were abnormal, while $13 \%$ of the brain sample values from asphyxiated infants without brain swelling were outside the control ranges. In the swollen brains abnormal water concentrations were higher than the control range, but in some infants without brain swelling the water content was abnormally low. Electrolyte abnormalities followed a consistent pattern, sodium concentration being increased and potassium decreased.

When examined as individual cases brain sample values outside the control ranges were found to be limited to 10 infants. Samples from two infants (cases 14 and 15) gave only one abnormal value, while in eight infants (cases 1,2 , $3,4,5,9,10$, and 13) including all cases with brain swelling, three or more brain sample values were outside the control ranges. Potassium depletion was found in a majority of samples from infants with brain swelling. In two instances an abnormal brain sample value was accompanied by the same abnormality in muscle; in cases 4 and 9 the sodium concentration was elevated in brain and muscle, but in both of these infants other brain sample abnormalities were also present.

A consistent relationship was found between abnormalities of brain water concentration and survival time. Increased brain water concentration was recorded only in infants who survived for 48 hours or longer, while a decreased water concentration was seen only in infants dying in the first 48 hours after birth. Electrolyte disorders occurred at all stages of survival, both with increased and with decreased water concentrations.

The possible effects of postmortem degeneration are examined in Table 4, which indicates that there was no overall relationship between postmortem interval and brain water and electrolyte concentrations. Correlation coefficients for post mortem intervals and water concentrations in cerebral cortex in infants at 32-37 weeks' gestation reached a significance level, showing an increase in water concentration with time, but there was no significant correlation between post mortem intervals and cortical water concentrations in infants at 38-42 weeks' gestation or in white matter samples in both gestational age groups. No significant correlation was found between post mortem intervals and sodium concentrations. Correlation coefficients for post mortem intervals and potassium concentrations in cerebral cortex reached a

TABLE 4

CORRELATION COEFFICIENTS FOR POSTMORTEM INTERVALS AND BRAIN WATER AND ELECTROLYTE CONCENTRATIONS

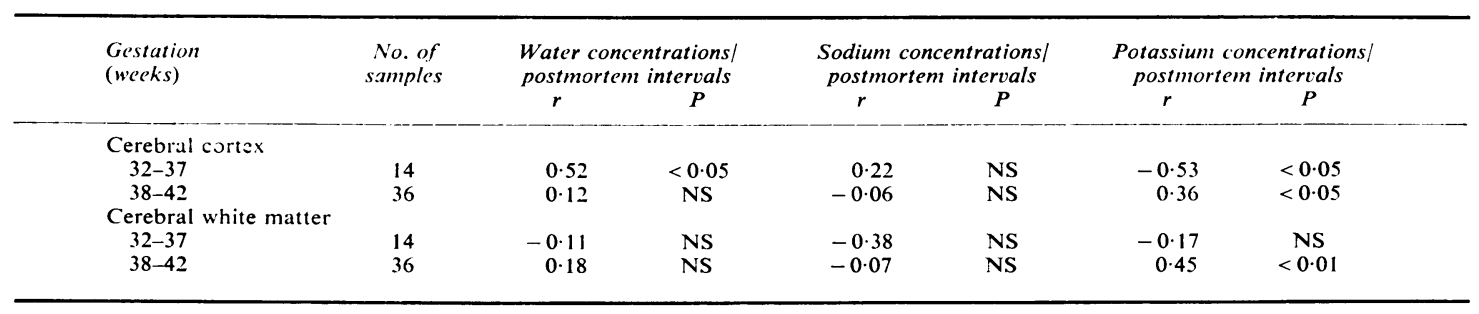


TABLE 5

INCIDENCE OF BRAIN WATER AND ELECTROLYTE ABNORMALITIES IN SEVERELY ASPHYXIATED INFANTS WITH AND WITHOUT DEXAMETHASONE TREATMENT

\begin{tabular}{|c|c|c|c|c|c|c|}
\hline & \multirow{2}{*}{$\begin{array}{c}\text { Total no. of } \\
\text { asphyxiated } \\
\text { infants } \\
\text { (liveborn) }\end{array}$} & \multirow{2}{*}{$\begin{array}{c}\text { Mean } \\
\text { survival } \\
\text { time } \\
(\text { hr })\end{array}$} & \multicolumn{4}{|c|}{ Infants with brain water and electrolyte abnormalities (no.) } \\
\hline & & & $\begin{array}{l}\text { High water } \\
\text { concentration }\end{array}$ & $\begin{array}{l}\text { Low water } \\
\text { concentration }\end{array}$ & $\begin{array}{l}\text { High sodium } \\
\text { concentration }\end{array}$ & $\begin{array}{l}\text { Low potassium } \\
\text { concentration }\end{array}$ \\
\hline $\begin{array}{l}\text { Dexamethasone } \\
\text { No dexamethasone }\end{array}$ & $\begin{array}{l}5 \\
6\end{array}$ & $\begin{array}{l}57 \\
32\end{array}$ & $\begin{array}{l}2 \\
1\end{array}$ & $\begin{array}{l}2 \\
1\end{array}$ & $\begin{array}{l}3 \\
2\end{array}$ & $\begin{array}{l}4 \\
1\end{array}$ \\
\hline
\end{tabular}

significance level; however, the relationship was negative in infants at 32-37 weeks' gestation, whereas it was positive in infants at 38-42 weeks' gestation.

Table 5 shows that a higher incidence of abnormal water and electrolyte values was found in infants selected for treatment with dexamethasone than in those who did not receive steroid treatment.

\section{DISCUSSION}

In the first days of life, infants who have been severely asphyxiated at birth may show clinical signs of cerebral irritation which are widely believed to be attributable to cerebral oedema. The present work goes some way to confirming this impression by showing that a substantial proportion of infants who experience severe intrapartum asphyxia and die within one week of birth have abnormalities of brain water or electrolyte concentration, and that pathological signs of brain swelling may ultimately develop in such cases. Our findings are also in keeping with the experimental work of Myers et al. (1969), which has shown that a prolonged partial asphyxial insult induces brain swelling in the fetal monkey.

Most of the control infants, particularly those with the respiratory distress syndrome, were hypoxic and hypercapnoeic during life, pointing to cerebral ischaemia as the main pathophysiological difference between the test and control groups and suggesting that brain water and electrolyte abnormalities in asphyxiated infants without cerebral cortical necrosis represent pre-necrotic ischaemic brain damage. Experiments designed to examine the effects of hypoxia and hypercapnoea without cerebral ischaemia have demonstrated that in adult cast brain water and electrolyte concentrations remain unchanged if the blood pressure is maintained (Norris and Pappius, 1970). Arterial blood pressure is not usually recorded in newborn infants, but infants with a low Apgar score have bradycardia and may even have episodes of cardiac arrest at the time of birth. Furthermore, experiments with fetal lambs and monkeys have shown that asphyxia causes a fall in heart rate and blood pressure (Dawes, 1968). The import $\vec{D} \vec{A}$ ance of ischaemia in the causation of braie $\frac{1}{3}$ damage at the time of birth is also illustrated by the neuropathological findings in spastic and mentally deficient survivors of abnormal births many of whom show lesions which are un $\overrightarrow{0}$ doubtedly the result of prolonged hypotensio (Norman et al., 1957; Norman, 1963).

Additional evidence that ischaemia contributes to the brain water and electrolyte disorders in asphyxiated infants without cortical necrosis is that these changes are of the same character as found in frankly necrotic brain tissue (for example, case 1). Similar changes have been reported in anoxic-ischaemic cerebral necrosis in adult rats (Plum et al., 1963) and dogs (Shibata et al., 1972), and also in fatally asphyxiated 5 day old rats (Adlard and De Souza, 1973); in all of these studies an increase in brain sodium concentration was found with a decrease in potassium concentration. In our study brain swelling was associated with a particularly high $\bigcirc$ incidence of electrolyte abnormalities, suggesting that this represents well-established ischaemic encephalopathy. A further point indicating that frank cerebral oedema in asphyxiated infants is the result of ischaemic damage at birth is that $\triangle$ three of the infants with brain swelling (cases 2 , 3 , and 4) died three to five days after birth, and 
from studies in adult subjects it is recognized that the oedema accompanying large cerebral infarcts is maximal three to five days after the onset of illness (Shaw et al., 1959).

It is important to consider the relative importance of asphyxia and trauma in the causation of water and electrolyte disturbances in the brain because some asphyxiated infants inevitably receive a degree of cranial trauma during birth. Two infants in the asphyxiated group had lacerations of tentorium cerebelli, but only one showed abnormal brain water and electrolyte values, and one infant in the control group also had tentorial lacerations. This would seem to suggest that asphyxia is more important than trauma as a cause of brain water and electrolyte abnormalities in newborn infants. However, the accurate assessment of brain trauma in newborn infants presents some difficulty, for brain contusion without dural laceration or bleeding is not easily detected at necropsy.

When studying human necropsy material it is clearly necessary to take account of the possible effects of post mortem degeneration, particularly when the interval from death to postmortem examination is variable. De Souza and Dobbing (1971) followed the post mortem water and electrolyte alterations in the adult rat brain for four days after death and found that the water and sodium concentrations increased by about $1 \%$ and $5 \%$ respectively, and potassium concentration decreased by about $20 \%$. These changes were attributed to equilibration of brain and cerebrospinal fluid electrolytes and were maximal in the first 12 hours after death, only minor alterations occurring after 24 hours. All of our control cases and also each of the cases with brain swelling were examined more than 24 hours after death, and no case was examined before 14 hours after death. Most of the post mortem electrolyte shift is therefore likely to have occurred before sampling and all cases may reasonably be considered to be affected to about the same extent by this shift. This conclusion is supported by the lack of a consistent correlation between water and electrolyte values and postmortem intervals (Table 4).

It is probable that the higher incidence of brain water and electrolyte disorders in the infants treated with dexamethasone is a reflection of case selection, indicating that the most severely affected cases were chosen for treatment. Studies of the effects of dexamethasone on the water and electrolyte content of brain tissue in human subjects with cerebral neoplasms (Reulen et al., 1972) and in experimental animals after trauma (Hansebout et al., 1972; Lewin et al., 1972), and cold injury (Pappius, 1972) have given conflicting results but do not suggest that dexamethasone might actually cause water and electrolyte abnormalities in the brain. Indeed, there is considerable evidence from clinical and experimental studies for the beneficial effects of dexamethasone on traumatic and ischaemic lesions of the mature brain associated with oedema (Reulen and Schurmann, 1972) and it seems reasonable to suppose that dexamethasone should sometimes be of value for birth asphyxia encephalopathy. In support of this view, Adlard and De Souza (1973) have found that pre-treatment with dexamethasone in a dose of $20 \mathrm{mg} / \mathrm{kg}$ prevents brain water and electrolyte changes in asphyxiated fetal rats, although the usual clinical dose of $1 \mathrm{mg} / \mathrm{kg}$ was ineffective in their experiments. Electrolyte abnormalities appear to develop in the first day after birth and to precede brain swelling in the human infant as in the fetal monkey (Selzer et al., 1972) suggesting that to have the best effect dexamethasone should be commenced as soon as possible and before clinical signs of brain swelling are present. However, before such treatment is widely adopted for severely asphyxiated infants, some form of clinical trial would be desirable in view of the evidence from fetal rat experiments that the drug may cause decreased brain growth (Adlard and De Souza, 1973).

We wish to thank Professor J. O. Forfar for his encouragement of this study, and Mrs. Sandra Leadbetter for technical assistance. The work was supported by a grant from the McGhie Fund of the University of Edinburgh.

\section{REFERENCES}

Adlard, B. P. F., and De Souza, S. W. (1973). Brain electrolytes and lysosomal enzymes in the asphyxiated five-dayold rat: effect of pretreatment with dexamethasone. Biochemical Society Transactions, 1, 120-123.

Apgar, V. (1953). Proposal for a new method of evaluation of the newborn infant. Current Researches in Anesthesia and Analgesia, 32, 260-267.

Brown, J. K, Purvis, R. J., and Forfar, J. O. (In preparation.) 
Dawes, G. S. (1968). Foetal and Neonatal Physiology. Year Book: Chicago.

De Souza, S. W., and Dobbing, J. (1971). Cerebral edema in developing brain. 1. Normal water and cation content in developing rat brain and postmortem changes. Experimental Neurology, 32, 431-438.

Hansebout, R. R., Lewin, M. G., and Pappius, H. M. (1972). Evidence regarding the action of steroids in injured spinal cord. In Steroids and Brain Edema, pp. 153-155. Edited by H. J. Reulen and K. Schürmann. Springer: Berlin.

Lewin, M. G., Pappius, H. M., and Hansebout, R. R. (1972). Effects of steroids on edema associated with injury of the spinal cord. In Steroids and Brain Edema, pp. 101-112. Edited by H. J. Reulen and K. Schürmann. Springer: Berlin.

Myers, R. E., Beard, R., and Adamsons, K. (1969). Brain swelling in the newborn rhesus monkey following prolonged partial asphyxia. Neurology (Minneap.), 19, 1012 1018.

Norman, R. M. (1963). Late neuropathological sequelae of birth injury. In Greenfield's Neuropathology, pp. 384-397. 2nd edn. Edited by W. Blackwood, W. H. McMenemey, A. Meyer, R. M. Norman, and D. S. Russell. Arnold: London.

Norman, R. M., Urich, H., and McMenemey, W. H. (1957). Vascular mechanisms of birth injury. Brain, 80, 49-58.

Norris, J. W., and Pappius, H. M. (1970). Cerebral water and electrolytes. Effect of asphyxia, hypoxia, and hypercapnia. Archives of Neurology (Chic.), 23, 248-258.
Pappius, H. M. (1972). Effects of steroids on cold injury edema. In Steroids and Brain Edema, pp. 57-63. Edited by H. J. Reulen and K. Schürmann. Springer: Berlin.

Plum, F., Posner, J. B., and Alvord, E. C., Jr. (1963). Edema and necrosis in experimental cerebral infarction. Archives of Neurology (Chic.), 9, 563-570.

Pryse-Davies, J., and Beard, R. W. (1973). A necropsy study of brain swelling in the newborn with special reference to cerebellar herniation. Journal of Pathology, 109, 51-73.

Reulen, H. J., Hadjidimos, A., and Schürmann, K. (1972). The effect of dexamethasone on water and electrolyte content and on regional cerebral blood flow in perifocal brain edema in man. In Steroids and Brain Edema, pp. 239-252. Edited by $\mathbf{H}$. J. Reulen and $\mathrm{K}$ Schürmann. Springer: Berlin.

Reulen, H. J., and Schürmann, K. (eds) (1972). Steroids and Brain Edema. Springer: Berlin.

Selzer, M. E., Myers, R. E., and Holstein, S. B. (1972). Prolonged partial asphyxia: effects on fetal brain water and electrolytes. Neurology (Minneap.), 22, 732-737.

Shaw, C. M., Alvord, E. C., Jr., and Berry, R. G. (1959) Swelling of the brain following ischemic infarction with arterial occlusion. Archives of Neurology (Chic.), 1, 161 177.

Shibata, S., Norris, J. W., Hodge, C. P., and Pappius, H. M. (1972). Effects of ischemia on water and electrolyte content of cerebral tissues. In Steroids and Brain Edema, pp. 123-125. Edited by H. J. Reulen and K. Schürmann. Springer: Berlin. 